\title{
Radiotherapy of Cholangiocarcinoma
}

\author{
Thomas B. Brunner, Mathias Walke, Peter Hass
}

Corresponding author:

Deparment for Radiotherapy

Otto-von-Guericke-University Magdeburg

Medical Faculty

Leipziger Str. 44, 39120 Magdeburg

Telefon: +49 $39167-15791$

Telefax: +49 $39167-15324$

E-mail: thomas.brunner@med.ovgu.de

www.med.uni-magdeburg.de
Department of Radiation Oncology, Universitätsmedizin Magdeburg, Otto-von-GuerickeUniversität, Leipziger Str. 14, 39120, Magdeburg, Germany

\section{ABSTRACT}

Unresectable cholangiocarcinoma represents a major therapeutic challenge and outcomes are still not satisfactory. However, there is the hope that recent developments in radiotherapy such as stereotactic body radiotherapy, proton therapy and brachytherapy are able to not only lead to better local control but also to prolong overall survival. Specific bowel protection strategies such as simultaneous integrated protection are required to safely deliver the dose in situations where there is close proximity of the lesions to the bowel. The integration of these techniques into the multimodal treatment approach is thought to become the new standard of care over the coming years. We here review the current state of stereotactic body radiotherapy and high dose rate interstitial brachytherapy.

Key words: cholangiocarcinoma, stereotactic body radiotherapy, simultaneous integrated boost, simultaneous integrated protection, high-dose-rate interstitial brachytherapy

\section{INTRODUCTION}

Cholangiocarcinoma is a cancer type that has its origin in bile duct epithelium. About half of the tumours arise at or around the hepatic hilum (perihilar cholangiocarcinoma, $\mathrm{PHC}$ ), $40 \%$ in the extrahepatic bile duct (EHC) and $10 \%$ in the bile duct system of the liver parenchyma (intrahepatic cholangiocarcinoma, IHC). Gallbladder cancer (GBC) is more frequent than any of these but it has a different pathological biology with a higher preponderance of systemic disease compared to bile duct cancer which has a tendency towards loco-regional growth patterns. There is a great deal of variation in the incidence of cholangiocarcinoma worldwide. GBC has the highest incidence in Europe in the north-eastern regions, whereas IHC peaks in south-east Asia which is attributed to endemic liver fluke infestation in that region.

Pathologically, cholangiocarcinoma is almost invariably adenocarcinoma. GBC frequently directly invades the liver and about $40-50 \%$ of patients have distant metastasis at presentation either to the liver or the peritoneum. Lymphatic spread is found in cystic, pericholedochal, hilar and coeliac lymph nodes in almost half of the patients. Cholangiocarcinoma is known to spread by direct extension along the biliary tree and direct invasion of adjacent organs is a 
feature of IHC and PHC however rare in EHC. Lymph nodes are positive in $30-50 \%$ of patients, typically found in cystic, hilar or coeliac lymph nodes. Distant metastases are found in around $1 / \beta$ of the patients in cholangiocarcinoma.

Imaging of both, GBC and cholangiocarcinoma predominantly relies on computed tomography (CT) and magnetic resonance imaging (MRI). Additionally, endoscopy in combination with endoscopic retrograde pancreaticocholangiography (ERCP) or MRI pancreaticocholangiography (MRCP) are important imaging modalities. 6-fluorodeoxyglucose positronvemission tomography/computed tomography (FDG-PET/CT) is an imaging technique that is predominantly used for planning purposes of radio-therapy for accurate tumour volume delineation. Elevated tumour markers such as carcinoma embryonic antigen (CEA) and carbohydrate antigen 19-9 (CA 19-9) can be valuable for follow-up of patients with cholangio-carcinoma. Biopsy proof of disease is recommended prior to therapy, however this can be especially difficult in PHC.

Primary therapy for gallbladder cancer is resection for patients without signs for distant metastasis, but only $10-30 \%$ of the patients can be considered for surgery at presentation. Since local failure after cholecystectomy for GBC's common, adjuvant therapy consisting in chemotherapy and radiotherapy play a role. For IHC, complete resection is the most effective and the only potentially curative treatment. Frequently IHC are locally advanced at presentation, hampering complete resection rates. Resection is also the primary treatment of choice for PHC and EHC tumours. However for PHC tumours resection is frequently not possible due its central location with invasion of right and left-sided hilar structures.

Radiotherapy for tumours in the liver and the liver hilum has been limited up until recently. Conventional radiotherapy was only able to treat targets in that region to palliative doses due to the radiation sensitivity of the liver. However, it became possible to deliver high radiation doses in the liver and the liver hilum after technical developments that took place at the end of the $20^{\text {th }}$ century. These techniques are intensity modulated radiotherapy (IMRT), image guided radiotherapy (IGRT), and stereotactic body radiotherapy (SBRT) as for percutaneous methods. Motion management strategies are a prerequisite of SBRT in the upper abdomen but these have now been developed to a satisfactory level in common practice. Also, brachytherapeutic methods were established to complement other local ablative therapies for tumours in the liver (1). Last but not least proton therapy was also found to be feasible and effective in cholangiocarcinoma due to the Bragg peak that leads to a dramatic reduction of exit doses (2).

As proton therapy is dealt with by another article in this issue of the journal, this article does not elaborate on proton therapy. Also, there is not sufficient room to cover adjuvant radiotherapy and conventionally fractionated (chemo)radiotherapy for biliary cancer and we therefore refer to a recently published review on this topic (3).

\section{Stereotactic body radiotherapy}

Stereotactic body radiotherapy (SBRT) is a technique of external beam irradiation either with photons or with particles that is defined by a high precision treatment with a few fractions to a high dose to an extracranial target (4). In contrast to the US American restriction to a maximum number of five fractions, the European definition is more relaxed about fraction number which can range between a single fraction up to twelve fractions. Recently, the dose prescription and dose reporting of SBRT was regulated by the International Commission on Radiation Units and Measurements report 91 (ICRU 91) that aims to lead to better comparison of SBRT between institutions (ICRU 91).

Compared to liver metastases and hepatocellular carcinoma (HCC), the role of SBRT has been less established for cholangiocarcinoma which is mostly due to the rarity of the disease compared to the other two tumour entities (table 1). Nevertheless, a number of groups has investigated SBRT to achieve high doses of radiotherapy locally. Among these studies there was a preponderance to intrahepatic tumours as these provide the same challenges compared to HCC and liver metastases. The vast majority of the studies is retrospective, and the typical indication is unresectable, locally advanced disease. Karnofsky performance status (KPS) is typically between $70 \%$ and $100 \%$ in the studies.

The results of studies on SBRT in cholangiocarcinoma are summarised in table 1 . Most series are small in numbers and retrospective. Throughout the studies there is neither a clear cut-off value for the number of lesions nor of maximum tumour size. The majority of the studies reported one year local control (LC) rates above $75 \%$. A number of trials found a correlation between dose and local control rate $(5,6)$ and the typical SBRT table mount dose distribution with high maximum doses and mean dose values was also described to correlate with local control (6). In studies that employed high radiotherapy doses a tendency of progressive disease outside of the radiotherapy volume rather than inside 
Table 1 - Review of literature on SBRT

\begin{tabular}{|c|c|c|c|c|c|c|c|c|}
\hline Authors & Study & Localization & $\begin{array}{l}\text { Nr. of } \\
\text { Lesions }\end{array}$ & $\begin{array}{l}\text { Nr. of } \\
\text { Fractions }\end{array}$ & $\begin{array}{l}\text { Total Dose } \\
\text { (Gy) }\end{array}$ & LC @ 1year & $\begin{array}{l}\text { Median OS } \\
\text { (months) }\end{array}$ & $\begin{array}{l}\text { Late Toxicity } \\
\text { (CTCAE) }\end{array}$ \\
\hline Barney (18) & $\mathrm{R}$ & $\begin{array}{l}\mathrm{IHC} \\
\mathrm{P} / \mathrm{EHC}\end{array}$ & $\begin{array}{l}6 \\
4 \\
\end{array}$ & $3-5$ & $45-60$ & $100 \%$ & 15.5 & $\begin{array}{l}1 \text { Grade } 3 \text { biliary stenosis, } \\
1 \text { Grade } 5 \text { liver failure }\end{array}$ \\
\hline Gkika (14) & $\mathrm{R}$ & $\begin{array}{l}\text { IHC } \\
\mathrm{P} / \mathrm{EHC}\end{array}$ & $\begin{array}{l}17 \\
26\end{array}$ & $3-12$ & $21-66$ & $78 \%$ & 14 & 3 Grade $\geq 3$ \\
\hline Goodman (19) & $\mathrm{P}$ & $\begin{array}{l}\mathrm{IHC} \\
\mathrm{P} / \mathrm{EHC}\end{array}$ & $\begin{array}{l}5 \\
0\end{array}$ & 1 & $18-30$ & $77 \%$ & 28.6 & None \\
\hline Ibarra (20) & $\mathrm{R}$ & $\begin{array}{l}\text { IHC } \\
\text { P/EHC }\end{array}$ & $\begin{array}{l}11 \\
0\end{array}$ & 3 & $22-50$ & $55.5 \%$ & 11 & $3 \mathrm{Grad} 3$ \\
\hline Jung (21) & $\mathrm{R}$ & $\begin{array}{l}\text { IHC } \\
\text { P/EHC }\end{array}$ & $\begin{array}{l}33 \\
25 \pm\end{array}$ & $1-5$ & $15-60$ & $85 \%$ & 10 & $\begin{array}{l}6 \text { Grade } 3 \text { (ulceration, } \\
\text { cholangitis, stenosis, perforation) }\end{array}$ \\
\hline Kopek (7) & $\mathrm{R}$ & $\begin{array}{l}\mathrm{IHC} \\
\mathrm{P} / \mathrm{EHC}\end{array}$ & 26 & 3 & 45 & $85 \%$ & 10.6 & $\begin{array}{l}6 \text { ulcerations } \\
3 \text { stenosis }\end{array}$ \\
\hline Mahadevan (22) & $\mathrm{R}$ & $\begin{array}{l}\mathrm{IHC} \\
\mathrm{P} / \mathrm{EHC}\end{array}$ & $\begin{array}{l}31 \\
11\end{array}$ & $3-5$ & $24-45$ & $88 \%$ & 17 & $\begin{array}{l}4 \text { Grade } 3 \text { (ulceration, } \\
\text { cholangitis, abscess) }\end{array}$ \\
\hline Momm (23) & $\mathrm{R}$ & $\begin{array}{l}\mathrm{IHC} \\
\mathrm{P} / \mathrm{EHC}\end{array}$ & $\begin{array}{l}0 \\
13\end{array}$ & $10-12$ & $32-56$ & $78 \%$ & 33.5 & $\begin{array}{l}1 \text { Grade } 3 \\
5 \text { cholangitis }\end{array}$ \\
\hline Polistina (24) & $\mathrm{R}$ & $\begin{array}{l}\text { IHC } \\
\text { P/EHC }\end{array}$ & $\begin{array}{l}0 \\
10\end{array}$ & 3 & $30^{\star}$ & $80 \%$ ** & 35.5 & $\begin{array}{l}1 \text { ulceration } \\
2 \text { stenosis }\end{array}$ \\
\hline Sandler (25) & $\mathrm{R}$ & $\begin{array}{l}\text { IHC } \\
\mathrm{P} / \mathrm{EHC}\end{array}$ & $\begin{array}{l}6 \\
25 \\
-\end{array}$ & 5 & 40 & $78 \%$ & 15.7 & 5 Grade $\geq 3$ \\
\hline Tao (5) & $\mathrm{R}$ & $\mathrm{IHC}$ & 79 & $15-30$ & & & $\begin{array}{l}3 y: \text { BED } \\
\leq 80.545 \% \\
>80.578 \%\end{array}$ & \\
\hline Tse (26) & $\mathrm{P}$ & $\begin{array}{l}\text { IHC } \\
\text { P/EHC }\end{array}$ & $\begin{array}{l}10 \\
0\end{array}$ & 6 & $28-48$ & $65 \%$ & 15 & $\begin{array}{l}1 \text { biliary obstruction } \\
1 \text { bowel obstruction }\end{array}$ \\
\hline Weiner (27) & $P$ & $\begin{array}{l}\text { IHC } \\
\text { P/EHC }\end{array}$ & $\begin{array}{l}12 \\
0\end{array}$ & 5 & $40-55$ & $91 \% \S$ & 13.2 & $\begin{array}{l}1 \text { hepatic failure } \\
1 \text { biliary stricture }\end{array}$ \\
\hline Brunner (6) & $\mathrm{R}$ & $\begin{array}{l}\mathrm{IHC} \\
\mathrm{PHC} \\
\mathrm{EHC}\end{array}$ & $\begin{array}{l}41 \\
31 \\
3\end{array}$ & $3-12$ & $\begin{array}{l}67.2 \\
(36-115) \\
(B E D)\end{array}$ & $89 \%$ & 15 & 3 Grade $\geq 3$ \\
\hline
\end{tabular}

Abbreviations:

R: retrospective, P: prospective, IHC: intrahepatic cholangiocarcinoma, EHC: extrahepatic cholangiocarcinoma, PHC: perihilar cholangiocarcinoma

${ }^{*}$ concurrent Gemcitabine

${ }^{* *}$ local response ratio

\pm 5 patients treated with conventional fractionation with a stereotactic boost

§In this study SBRT was performed also in patients with hepatocellular carcinoma. LC and toxicities are reported for the whole group of patients including

hepatocellular and cholangiocarcinoma.

was described (7). The the preferred location of disease progression was in the liver, in abdominal lymph nodes and in the lungs $(8,9,10)$. Results for median overall survival (OS) varied between 10 months and 35 months. Median OS was $<15$ months in only five of 17 studies. Three patients had a median overall survival of $\geq 24$ months. Patients with positive lymph nodes were also included in the studies. Furthermore, dose was reported to prolong survival in two trials $(5,6)$. Interestingly, patients receiving a maximal biological equivalent dose at $\alpha / \beta=10$ (BED10max) $>91$ Gy had a median OS of 24 months vs. 13 months for those receiving lower doses $(p=0.015)$ in the trial from the German working group of stereotactic radiotherapy (6) and prescribed encompassing dose was not statistically significant for survival. Thus, the typical non-homogeneous dose distribution appears to be of high importance for both endpoints, local control and overall survival. In the MD Anderson series where
15-30 fractions were prescribed, a dose of $>80.5 \mathrm{~Gy}$ correlated with prolonged survival compared to lower doses (median not reached versus 27 months) (5).

\section{SIMULTANEOUS INTEGRATED PROTECTION (SIP) AS A CONCEPT FOR BOWEL PROTECTION IN PATIENTS TREATED WITH RADIOTHERAPY FOR CHOLANGIOCARCINOMA}

Proximity of bowel structures to target lesions is a significant problem for SBRT. This is especially true for PHC tumours where frequently contact to the duodenum is an obstacle for high doses of radiotherapy. The situation resembles that of pancreatic cancer, also a tumour with intimate spatial relation to the duodenum or stomach. For pancreatic cancer a meta-analysis found a dose-toxicity relationship which is also useful for cholangiocarcinoma (4). Our group has 
used this relationship as a basis for a concept that we have termed 'simultaneous integrated protection' (SIP) (12). In analogy to the simultaneous integrated boost (SIB) technique, a subvolume of the planning target volume (PTV) receives a different dose, in this case a lower dose to protect bowel structures. The SIP volume is defined by the intersection volume of the PTV with the planning risk volume (PRV) of the critical organ at risk (OAR, fig. 1). A rule of thumb is that in case of significant contacts a higher fraction number is used for interfractional recovery of the bowel, i.e. we often would chose 8 or 12 fractions in such cases delivered every other day or with a planned break on Wednesdays. This approach appears to be safe as reported in a few reports now, one on pancreatic cancer, one on cholangiocarcinoma SBRT and one on hypo- and normofractionated radiotherapy $(5,13,14)$. The concept of SIP is explained in further detail in a video on a webpage (https://www.uniklinik-freiburg.de/strahlenklinik/ studienportal.html) under the heading 'SIP'.

\section{BRACHYTHERAPY}

High dose rate interstitial brachytherapy (HDR-iBT) with iridium-192 is another technique that can be used to treat cholangiocarcinoma (fig. 2). Compared to SBRT it has the advantage that for large lesions protection of the healthy liver tissue is easier to achieve. Also high

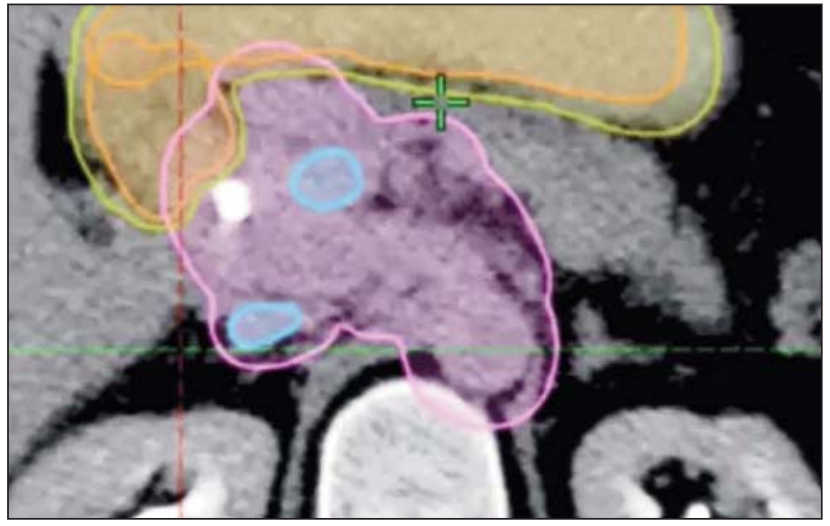

Figure 1 - An illustration of the SIP concept in a patient with a Klatskin tumour who received SBRT in 12 fractions. Example of a patient with a Klatskin tumour and 6-FDG-PET/CT positive lymph nodes (blue) in the hepatoduodenal ligament. The PTV (pink) overlaps with stomach and duodenum (orange) with the PRV of the stomach and duodenum. The overlapping subvolume of the PTV with the PRV is the SIP volume and the large remainder the dominant PTV that can safely be prescribed full dose

maximal doses as in SBRT can be given which are especially important in few fractions. The prescribed minimum dose for the clinical target volume recommended is $20 \mathrm{~Gy}$. Specifically in patients where radiofrequency ablation (RFA) is not feasible owing to larger tumor sizes $(>5 \mathrm{~cm}$ ) or adjacent, potentially cooling structures such as larger vessels, HDR-iBT is a useful option. A retrospective analysis of local
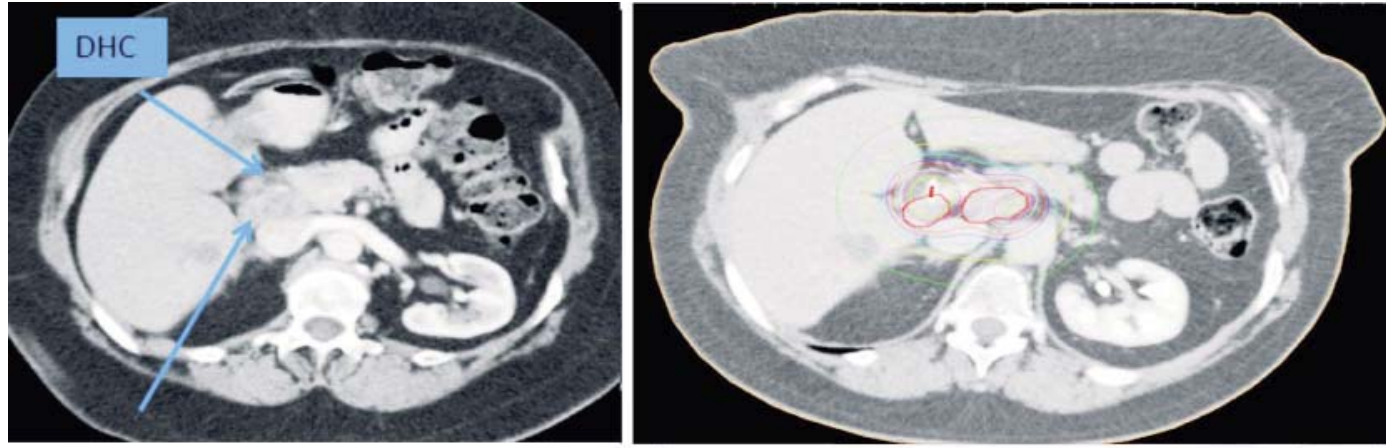

Figure 2 - An example for HDR-iBT to central liver targets, in this case lymph nodes in the perihilar region. Panel A shows a pretherapy contrast-enhanced CT scan (portalvenous phase). Panel B is the planned dose of that same case and Panel $C$ is a $3 D$ reconstruction showing also the placement of three catheters into the lesion. DHC = ductus hepaticus communis, i.e. common hepatic bile duct

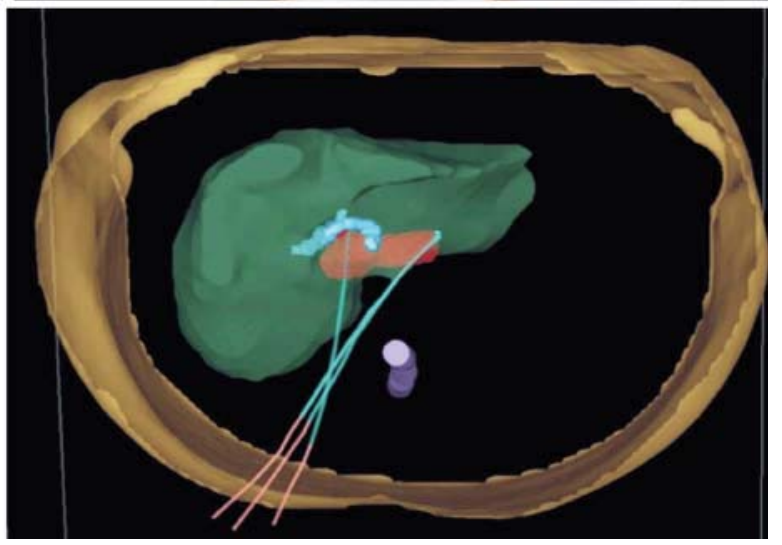


treatment strategies comprised 45 patients who had 101 sessions of iBT (15). Three patients developed grade 3 toxicities being abcess, shivering and haematoma in one each. In another series, Schnapauff et al. evaluated outcomes after repeated interstitial iBT (27 sessions) in 15 patients with unresectable ICC who did not show extrahepatic metastasis and suffered from limited hepatic disease only ( $<5$ lesions), revealing a median survival of 11 months and 21 months after primary diagnosis (1). Centrally located primary and secondary tumours in 41 patients with 50 lesions $>4$ $\mathrm{cm}$ in largest diameter were analyzed by Tselis et al (16). They were treated with a media dose of $20 \mathrm{~Gy}$ (7-32 Gy), twice daily (BID), with median single doses of 7 Gy (4-10 Gy) in 19 patients or in single daily fractions of a median of $8 \mathrm{~Gy}$ (7-14 Gy) in 22 patients. The achieved local control for primary hepatic tumours was $81 \%$ at 1 year and common terminology criteria for adverse events (CTCAE) grade $3 / 4$ side effects were observed in $5 \%$ of the patients. A series of 102 patients with lesions close to the bile ducts analyzed the frequency of cholestasis after iBT (17). Twenty-two patients developed cholestasis at a median 17 months post iBT and 18 were treated with bile duct stents. The best cutoff value for stenosis was an equivalent dose in 2 Gy of 100 Gy at $\alpha / \beta=3$ Gy (EQD23) with $p=0.028$, however occurrence of stenosis did not impact on survival despite of more frequent cholangitis and abscess formation.

\section{CONCLUSION}

Cholangiocarcinoma remains a significant, therapeutic that requires novel local treatment strategies. Modern radiotherapy solutions to this problem have been developed, namely SBRT, proton radiotherapy and brachytherapy. The close proximity of bowel structures poses a problem in a significant number of patients and one possible approach to be able to safely deliver radiotherapy could be simultaneous integrated protection (SIP).

\section{REFERENCES}

1. Schnapauff D, Denecke T, Grieser C, Collettini F, Seehofer D, Sinn M, et al. Computed tomography-guided interstitial hdr brachytherapy (ct-hdrbt) of the liver in patients with irresectable intrahepatic cholangiocarcinoma. Cardiovasc Intervent Radiol. 2012;35(3):581-7.

2. Hong TS, Wo JY, Yeap BY, Ben-Josef E, McDonnell El, Blaszkowsky LS, et al. Multi-institutional phase ii study of high-dose hypofractionated proton beam therapy in patients with localized, unresectable hepatocellular carcinoma and intrahepatic cholangiocarcinoma. J Clin Oncol. 2016;34(5):460-8.

3. Brunner TB, Seufferlein T. Radiation therapy in cholangiocellular carcinomas. Best Pract Res Clin Gastroenterol. 2016;30(4):593-602.

4. Sterzing F, Brunner TB, Ernst I, Baus WW, Greve B, Herfarth K, et al. Stereotactic body radiotherapy for liver tumors: Principles and practical guide- lines of the degro working group on stereotactic radiotherapy. Strahlenther Onkol. 2014;190(10):872-81.

5. Tao R, Krishnan S, Bhosale PR, Javle MM, Aloia TA, Shroff RT, et al. Ablative radiotherapy doses lead to a substantial prolongation of survival in patients with inoperable intrahepatic cholangiocarcinoma: A retrospective dose response analysis. J Clin Oncol. 2016; 34(3): 219-26.

6. Brunner TB, et al. Stereotactic body radiotherapy dose and its impact on local control and overall survival of patients for locally advanced intrahepatic and extrahepatic cholangiocarcinoma. submitted 2018.

7. Kopek N, Holt MI, Hansen AT, Høyer M. Stereotactic body radiotherapy for unresectable cholangiocarcinoma. Radiother Oncol. 2010;94(1):47-52.

8. Potters L, Steinberg M, Rose C, Timmerman R, Ryu S, Hevezi JM, et al. American Society for therapeutic radiology and oncology and American College of radiology practice guideline for the performance of stereotactic body radiation therapy. Int J Radiat Oncol Biol Phys. 2004;60(4):1026e32.

9. McGinn CJ, Ten Haken RK, Ensminger WD, Walker S, Wang S, Lawrence TS. Treatment of intrahepatic cancers with ra- diation doses based on a normal tissue complication probability model. J Clin Oncol 1998;16(6):2246e52.

10. Borgelt BB, Gelber R, Brady LW, Griffin T, Hendrickson FR. The palliation of hepatic metastases: results of the radiation therapy oncology group pilot study. Int J Radiat Oncol Biol Phys. 1981; 7(5):587e91.

11. Brunner TB, Nestle U, Grosu AL, Partridge M. SBRT in pancreatic cancer: what is the therapeutic window? Radiother Oncol. 2015; 114(1):109-16.

12. Brunner TB, Nestle U, Adebahr S, Gkika E, Wiehle R, Baltas D, et al. Simultaneous integrated protection : A new concept for high-precision radiation therapy. Strahlenther Onkol. 2016; 192(12):886-894.

13. Gkika E, Hallauer L, Kirste S, Adebahr S, Bartl N, Neeff HP, et al. Stereotactic body radiotherapy (sbrt) for locally advanced intra-hepatic and extrahepatic cholangiocarcinoma. BMC Cancer. 2017; 17(1):781.

14. Gkika E, Adebahr S, Kirste S, Schimek-Jasch T, Wiehle R, Claus R, et al. Stereotactic body radiotherapy (SBRT) in recurrent or oligo-metastatic pancreatic cancer: A toxicity review of simultaneous integrated protection (SIP) versus conventional SBRT. Strahlenther Onkol. 2017;193(6):433-443.

15. Seidensticker R, Seidensticker M, Doegen K, Mohnike K, Schütte K, Stübs P, et al. Extensive use of interventional therapies improves survival in unresectable or recurrent intrahepatic cholangiocarcinoma. Gastroenterol Res Pract. 2016; 2016:8732521.

16. Tselis N, Chatzikonstantinou G, Kolotas C, Milickovic N, Baltas D, Zamboglou N. Computed tomography-guided interstitial high dose rate brachytherapy for centrally located liver tumours: A single institution study. Eur Radiol. 2013; 23(8):2264-70.

17. Powerski M, Penzlin S, Hass P, Seidensticker R, Mohnike K, Damm R, et al. Biliary duct stenosis after image-guided high-dose-rate interstitial brachytherapy of central and hilar liver tumors: A systematic analysis of 102 cases. Submitted 2018.

18. Barney BM, Olivier KR, Miller RC, Haddock MG. Clinical outcomes and toxicity using stereotactic body radiotherapy (sbrt) for advanced cholangiocarcinoma. Radiat Oncol. 2012;7:67.

19. Goodman KA, Wiegner EA, Maturen KE, Zhang Z, Mo Q, Yang G, et al. Dose-escalation study of single-fraction stereotactic body radiotherapy for liver malignancies. Int J Radiat Oncol Biol Phys. 2010; 78(2):486-93.

20. Ibarra RA, Rojas D, Snyder L, Yao M, Fabien J, Milano M, et al. Multicenter results of stereotactic body radiotherapy (SBRT) for non-resectable primary liver tumors. Acta Oncol. 2012;51(5):575-83.

21. Jung DH, Kim MS, Cho CK, Yoo HJ, Jang WI, Seo YS, et al. Outcomes of stereotactic body radiotherapy for unresectable primary or recurrent cholangiocarcinoma. Radiat Oncol J. 2014; 32(3):163-9.

22. Mahadevan A, Dagoglu N, Mancias J, Raven K, Khwaja K, Tseng JF, et al. Stereotactic body radiotherapy (sbrt) for intrahepatic and hilar cholangiocarcinoma. J Cancer. 2015;6(11):1099-104.

23. Momm F, Schubert E, Henne K, Hodapp N, Frommhold H, Harder J, et al. Stereotactic fractionated radiotherapy for klatskin tumours. Radiother Oncol. 2010;95(1):99-102.

24. Polistina FA, Guglielmi R, Baiocchi C, Francescon P, Scalchi P, Febbraro A, et al. Chemoradiation treatment with gemcitabine plus stereotactic body radiotherapy for unresectable, non-metastatic, locally advanced hilar cholangiocarcinoma. Results of a five year experience. Radiother Oncol. 2011;99(2):120-3.

25. Sandler KA, Veruttipong D, Agopian VG, Finn RS, Hong JC, Kaldas FM, et al. Stereotactic body radiotherapy (SBRT) for locally advanced extrahepatic and intrahepatic cholangiocarcinoma. Adv Radiat Oncol. 2016;1(4):237-243.

26. Tse RV, Hawkins M, Lockwood G, Kim JJ, Cummings B, Knox J, et al. Phase i study of individualized stereotactic body radiotherapy for hepatocellular carcinoma and intrahepatic cholangiocarcinoma. J Clin Oncol. 2008;26(4):657-64.

27. Weiner AA, Olsen J, Ma D, Dyk P, DeWees T, Myerson RJ, et al. Stereotactic body radiotherapy for primary hepatic malignancies - report of a phase i/ii institutional study. Radiother Oncol. 2016; 121(1):79-85. 